\title{
Informática na Escola: uma visão da gestão
}

\author{
Karina Marcon ${ }^{1}$ Adriano Canabarro Teixeira ${ }^{2}$ \\ ${ }^{1}$ Doutoranda em Educação pelo Programa de Pós-Graduação em Educação da Universidade \\ Federal do Rio Grande do Sul (UFRGS) - Porto Alegre - RS - Brasil \\ ${ }^{2}$ Doutor em Informática na Educação (UFRGS), professor do Programa de Pós-Graduação \\ em Educação da Universidade de Passo Fundo (UPF) - Passo Fundo - RS - Brasil \\ kamarconegmail.com, teixeiraeupf.br
}

\begin{abstract}
Resumo: $O$ objetivo deste artigo é relatar uma experiência empírica sobre a visão da gestão de escolas municipais de Passo Fundo/RS sobre informática educativa. Buscou-se reconhecer os pontos positivos e negativos da concepção da gestão escolar sobre essas ferramentas disponíveis, além de compreender qual a relação das tecnologias digitais de rede nos processos educativos dessas escolas. Após a realização de um curso de formação docente, realizado sob um âmbito de inclusão digital, sentiu-se a necessidade de acompanhar seu desdobramento na prática escolar. Essa pesquisa desenvolveu-se na íntegra através de uma dissertação de mestrado e este artigo traz uma das categorias desenvolvidas, intitulada "Relação das Tecnologias de Rede com os processos educativos". Podemos concluir que a gestão reconhece a importância da inclusão digital de suas escolas, porém existe receio em utilizar as tecnologias pelo fato de não dominarem a técnica ou de não reconhecerem o potencial dessas ferramentas na dinâmica escolar.

Palavras-chave: inclusão digital, formação docente, informática educativa.
\end{abstract}

\begin{abstract}
This work describes an empirical study about a view of management schools of Passo Fundo/RS on educational informatics. Sought to recognize their positives and negatives points of the concept of school management about these tools available and understand what the relationship of digital technologies in the educational processes of these schools. After taking part in a teacher training course in Passo Fundo/RS, focused on digital inclusion, I felt the need of tracing its outcomes in school practice. The research was carried out along a master's dissertation study and this paper reports one of the categories involves, namely Value Network Technologies with the educational processes. We can conclude that management recognizes the importance of digital inclusion in their schools, but there is fear in using the technology because they do not dominate the technique or not to recognize the potential of these tools in the school dynamics.

Keywords: digital inclusion, teaching formation, educational computing.
\end{abstract}

\section{Introdução}

Constata-se que o debate acerca da informatização das escolas é pertinente, entretanto, na medida em que algumas escolas já estão informatizadas, é fundamental que se realizem 
processos de acompanhamento das transformações que esta nova realidade suscita ao cotidiano escolar.

Neste sentido, em Passo Fundo/RS foram realizados investimentos na informatização das escolas e também na formação docente, já que foi percebida uma demanda na qualificação dos educadores cujas escolas seriam informatizadas. Portanto, tornou-se fundamental um acompanhamento dos resultados das experiências de formação docente, com vistas a qualificar ainda mais os processos de inclusão digital da cidade.

Após a execução do projeto Formação Docente como exercício inclusivo de autoria colaborativa com cerca de 60 professores da rede municipal de ensino de Passo Fundo, sentiu-se a necessidade de acompanhar quais foram as mudanças ocorridas na prática dessas escolas.

Esse projeto foi realizado através de uma parceria entre Universidade de Passo Fundo e Prefeitura Municipal de Passo Fundo, e teve por objetivo propor, desenvolver e verificar a potencialidade de uma metodologia de formação docente baseada no conceito de inclusão digital. Foi desenvolvido através de um curso de 180 horas composto por cinco módulos. Os módulos previam, além da utilização do Kelix ${ }^{1}$, das ferramentas da internet e do Pacote BrOffice, a Construção de Projetos de Aprendizagem que pudessem explorar as possibilidades que um laboratório de informática pode propiciar na escola.

Após esse curso, sentiu-se a necessidade de realizar uma pesquisa de campo nas escolas cujos docentes participaram desse processo de formação. Foi realizada uma visita em cada escola, com o objetivo de aproximar-se da realidade do processo de apropriação das tecnologias. As turmas observadas variaram entre $3^{\mathrm{a}}$ e $4^{\mathrm{a}}$ séries. Foram entrevistados diretores, professores, monitores e alunos de sete das dez escolas envolvidas, em função de que em três escolas os laboratórios de informática não estavam funcionando.

Esse artigo faz um recorte da visão da gestão das escolas sobre os processos de informatização, reconhecendo os pontos positivos e negativos destacados. Ainda, procura compreender qual a relação das tecnologias disponíveis nos processos educativos, de acordo com os relatos de professores responsáveis pelos laboratórios e pelos monitores.

\section{Contextualizando o cenário}

Entendemos as tecnologias digitais de rede (TDR) como um suporte comunicacional multidirecional que potencializa os processos educativos, na medida em que contribui na interação entre alunos, professores e as próprias tecnologias.

Diante dessas características, essas tecnologias passam a possuir papel fundamental na sociedade contemporânea, uma vez que é através delas que a comunicação e o diálogo entre pessoas que não dispõem da condição presencial se efetivam. Acabam por se tornar, portanto, fundamentais na dinâmica de vida social, sendo assim instituída primeiramente a necessidade ao acesso às mesmas e posteriormente a apropriação destas de forma crítica e diferenciada das tecnologias convencionais, com o intuito que se produzam competências e que o ser humano se aproprie dessas TDR como um ser autônomo e protagonista (PRETTO, 2005; BONILLA, 2004; TEIXEIRA, 2005).

Percebida a necessidade de viver essa dinâmica, devem ser repensadas as articulações dos processos educativos a partir do potencial das redes. Se analisadas todas as características das redes, verifica-se que os processos educativos, com destaque aos formais e relacionados à

\footnotetext{
${ }^{1}$ Distribuição livre implementada nos laboratórios. Mais informações: kelix.upf.br
} 
escola, encontram-se numa situação desigual e geralmente não acompanham essa dinâmica social contemporânea.

Seja pela questão milenar que conduz as atividades da escola (LÈVY, 1999) ou pela formação dos professores que, de certa forma, não contempla os aspectos contemporâneos essenciais para uma educação emancipatória (FREIRE, 1976) - que acompanhe os rápidos movimentos da sociedade - o que se percebe é que ainda existem ações que distanciam a escola da dinâmica social contemporânea. Muitas vezes, a escola continua reproduzindo atividades que não estimulam o envolvimento, a participação, autoria e co-autoria, elementos essenciais para suprirem as inúmeras e diversas demandas de aprendizagens existentes na contemporaneidade (POZO, 2002).

Neste sentido, é essencial compreender a urgência dos processos de inclusão digital, bem como repensar a apropriação dos meios tecnológicos pela sociedade (BONILLA, 2004). Além do acesso, é preciso pensar nas outras dimensões da inclusão digital, quais sejam: compreensão da importância de uma apropriação crítica e criativa das TDR; consciência do potencial dessas tecnologias na dinâmica social contemporânea; entendimento do real significado da abertura dos canais de comunicação das TDR, ou seja, aspectos de autoria e coautoria; bem como buscar uma formação docente adequada, com o intuito de que todas essas características sejam assumidas pelos educadores que vivenciam todos esses processos na sociedade contemporânea e que acreditam na inclusão digital como propulsora de uma nova cultura de aprendizagem.

\title{
2 Pontos positivos e negativos das Tecnologias de Rede: visão da gestão
}

\begin{abstract}
"A princípio um receio: o que fazer com a máquina? O que propor? Uma vez acessando, percebi nos professores a emoção do encantamento, das possibilidades. O encantamento e a necessidade de trazer essa informação pro colega” (D06) ${ }^{2}$.
\end{abstract}

Para verificar as relações e contribuições das TDR nos processos educativos, optou-se por apresentar a visão dos gestores sobre os pontos negativos e positivos dessas tecnologias na dinâmica escolar.

Os diretores ou vice-diretores apresentaram, primeiramente, suas percepções sobre as reações - positivas e negativas - dos professores com a chegada do laboratório de informática na escola. Dois gestores ressaltam que a presença de um professor coordenador do laboratório facilitou o processo de adaptação dos professores à informática:

\footnotetext{
"No começo as professoras ficaram um pouco assustadas, não queriam se aproximar dos computadores. Depois começaram a sentir mais segurança, dialogando com a coordenadora do laboratório" (D04).

"Pela segurança de ter a professora responsável sempre junto e acompanhando, todos os professores procuraram utilizar o laboratório" (D03).
}

\footnotetext{
${ }^{2}$ Em relação à categorização dos sujeitos, todas as falas identificadas como D são das Direções; M dos monitores e P dos professores. Ao lado de todas elas foram colocados números - de 01 a 07 - que representam as sete escolas visitadas, sendo que todos os sujeitos que possuem ao lado de sua letra o número 01 são da mesma escola, assim como aqueles que possuem os outros números $(02,03,04,05,06$ e 07$)$.
} 
Percebe-se que a formação docente realizada com esse grupo de professores, sendo que alguns deles em seguida assumiram como coordenadores dos laboratórios, propiciou maior segurança para os demais professores das escolas que não passaram pelo Projeto de Formação Docente. Portanto, o investimento na formação dos coordenadores não auxiliou somente na relação direta da prática usual do laboratório, mas sim no surgimento de uma receptividade maior em relação à utilização do laboratório para aqueles professores que conhecem pouco ou quase nada de informática.

Também na percepção dos diretores sobre as reações positivas dos professores, foi recorrente a visão sobre o laboratório como elemento pedagógico auxiliador:

\begin{abstract}
“Alguns professores por não ter acesso em casa, não levam muito os alunos no laboratório, mas existe o interesse em mudar o tipo de aula, porque é um atrativo a mais" (D02).

“A aula é ampliada e fixada no laboratório, pois os professores têm mil alternativas pra eles usarem; na medida do possível sempre que está liberado, é utilizado" (P05).

"Houve um interesse bastante grande dos professores, que se sentiram motivados em ter mais um material disponível, uma sala disponível pra fazer um trabalho diferente. Todos ficaram bem felizes [...] em um sábado os professores vieram conhecer a sala de informática por interesse próprio, para conhecer os programas" (D01).
\end{abstract}

"No geral é ótimo pros professores, com certeza isso só veio a auxiliar o professor e os alunos adoram" (D07).

Dessas falas pode ser percebida uma questão importante, o fato dos professores não possuírem um computador em casa, elemento que por vezes pode vir a dificultar a utilização da informática nas suas aulas.

Apenas dois gestores mencionaram a existência de reações negativas dos professores diante da informática. Um diretor acredita que uma reação negativa foi diante da

"falta de pessoal para atender toda a demanda" (D05)

Essa falta de pessoal pode ter sido oriunda de um corte realizado pela Prefeitura, no qual muitos monitores dos laboratórios foram desligados, fato que certamente prejudicou andamento do processo e, de acordo com a fala do diretor, deixou os professores preocupados.

O outro diretor menciona como reação negativa o descaso de alguns professores:

"Principalmente professoras da área não valorizam tanto, porque como é por período, elas deveriam preparar aquilo que os alunos precisassem, acompanhar os alunos e ficar junto lá com eles, e, claro que não é no geral, mas um ou dois casos elas largam os alunos com a professora [coordenadora], que não é função dela, e descem pra cá, ou correm no mercado... acho que não é esse o objetivo da informática, as professoras têm que acompanhar o aluno pra saber se ele realmente ta pesquisando e se é aquilo" (D07). 
Nessa situação caberia a utilização da expressão segundo a qual o laboratório estaria sendo usado como um "depósito de alunos". Alguns professores que desconhecem o potencial da informática educativa "largam" seus alunos naquele ambiente, deixando para a professora responsável pelo laboratório não só a tarefa de orientar as dúvidas dos alunos, mas até mesmo de conduzir as aulas, papel que por ela não deveria ser desempenhado, de acordo com a fala da diretora.

Além da percepção dos gestores sobre as reações dos professores com a vinda do laboratório para a escola, também foram indagados a eles quais seriam os pontos positivos e negativos, nas suas percepções, que poderiam ser destacados a partir da presença e utilização dos laboratórios. Dos pontos positivos apontados, vozes semelhantes falam sobre um maior envolvimento e participação do aluno e da comunidade na dinâmica escolar, bem como o despertar do desejo de pesquisa:

\begin{abstract}
"Os alunos são mais participativos, cobram a ida ao laboratório" (D04).
"Euforia que as crianças têm em ter a internet na escola, os professores também gostam e se interessam, e o despertar do interesse e curiosidade dos alunos para pesquisar" (D07).

"A escola ficou mais atrativa para os alunos, eles se interessam muito em qualquer tipo de pesquisa, nem só de conteúdo de aula, mas qualquer coisa; a comunidade procurou bastante a escola" (D02).

"A motivação para o estudo da criança; a pesquisa, sair do convencional - livros - e entrar para o virtual, eles não têm isso, então é uma coisa que só acontece aqui, são poucos os que tem... e a própria aprendizagem" (D05).
\end{abstract}

Além dessas características, outro gestor aponta o sentimento de pertencimento da própria escola nessa inclusão, que passa também a poder exercer seus direitos na cibercultura:

\begin{abstract}
"As crianças ingressarem na era da tecnologia, porque algumas não tinham acesso a isso; a possibilidade dos professores fazer uma aula diferente, com um recurso diferente; a pesquisa poderá ser beneficiada, porque os professores das séries finais vão ter acesso e os alunos vão ter acesso a isso; a escola também se beneficiou por ganhar a internet, facilitando o trabalho... pretendemos criar e-mail e uma página da internet pra divulgar a escola" (D01).
\end{abstract}

Essa questão de pertencimento da própria escola na cibercultura lembra o que Pretto (2005) observa, a necessidade da integração entre a escola e a comunicação. É um fato que acontecerá no momento em que estes novos meios forem apropriados pela escola e pela dinâmica escolar, fazendo da escola um elemento participante na construção de uma nova sociedade, não permanecendo como espectadora dos novos valores em ascensão.

Outros dois diretores mencionaram como pontos positivos, entre outros, o desenvolvimento da própria linguagem: 


\begin{abstract}
"Havia uma expectativa muito grande em poder acessá-los; o despertar para outra forma de linguagem; o sentimento de orgulho em dizer que a sua escola tem laboratório de informática e acesso à internet; o comportamento das turmas em estarem cuidando e zelando pelo laboratório; instalação de todos os recursos..." (D06).

“A metodologia do uso do laboratório auxilia o aluno para a percepção, o imaginário, na matemática, na própria linguagem escrita e oral (português, redação), ensino lógico, a atenção e no próprio desenvolvimento da criança. Também porque a área tecnológica é a evolução do mundo, e isso influencia a criança pequena até seu desenvolvimento integral. As informações, o conhecimento geral e global, a pesquisa. Tudo está na internet" (D03).
\end{abstract}

Sabe-se que o desenvolvimento da linguagem pode ser potencializado pelas relações hipertextuais (LÉVY, 1999) da rede, colaborando para o desenvolvimento do ser, concepção que remete ao entendimento do próprio MEC (2007) sobre inclusão digital. É uma visão que se aproxima ao entendimento do grupo de formação docente (TRENTIN et al, 2007), pois este acredita que as TDR devem ser aproveitadas para preparar o novo cidadão e que os recursos tecnológicos sejam utilizados como auxiliares no processo de evolução humana, elementos demonstrados nesses discursos desses professores.

Já em relação aos pontos negativos da informática na escola, quatro dizem respeito a algumas questões de ordem técnica e em relação à estrutura existente:

"O laboratório chegou na escola em 2006 e houve uma grande demora na instalação, sendo que o mesmo só começou a funcionar em 2008; também a falta do monitor é um aspecto negativo" (D01).

"O programa Kumbuntu de vez em quando entra em pane, fecha e não abre mais, sendo que os computadores foram muitas vezes pro conserto. Há uma reivindicação para recolocar o Kelix na versão anterior novamente. Um pouco mais de máquinas seria bom também" (D06).

"Poucas máquinas, os recursos teriam que ser mais aproveitados e melhor distribuídos, as máquinas deveriam ser de acordo com o número de alunos da escola, porque não tem condições de atender 800 alunos com 10 máquinas, sendo que duas não estão funcionando. A internet que falha, computadores que estragam e a demora dos técnicos em arrumar..." (D07)

"Sala muito pequena, porque as turmas são muito grandes..." (D05).

Outros três gestores mencionam como pontos negativos algumas influências diretas relacionadas aos processos educativos:

\footnotetext{
"Quando abriu espaço para a pesquisa, os alunos não queriam mais pesquisar na biblioteca, somente na internet [...] o fato das crianças deixarem de ir na biblioteca é um aspecto negativo, pois na internet as crianças podem imprimir direto, sem nem mesmo ler o que pesquisaram. Uma alternativa encontrada foi fazer os alunos copiarem da tela para o caderno, para realmente ler o que pesquisaram” (D04).

"Exposição das crianças na internet, a pornografia que os alunos procuram na internet e a facilidade dos alunos maiores em acharem um trabalho pronto, principalmente da $6^{\mathrm{a}}, 7^{\mathrm{a}}$ e $8^{\mathrm{a}}$ série" (D03).
} 
Essas questões dos alunos "acharem os trabalhos prontos" realmente podem ser consideradas um problema para a dinâmica escolar. Entretanto, cabe salientar que isso não é um problema oriundo da internet. Sabe-se que a cópia sempre existiu, desde o tempo em que os alunos copiavam das grandes enciclopédias que tinham em casa. Com a tecnologia, o processo foi facilitado, mas o discernimento do professor em conhecer seus alunos, reconhecer suas potencialidades e saber identificar aqueles que realmente pesquisaram e fizeram o trabalho daqueles que simplesmente copiaram e colaram, é a melhor maneira de sanar o problema. Essa questão também pode reportar ao que Lemos (2003) escreveu sobre a segunda lei da cibercultura, a liberação do pólo da emissão, pois esse excesso de informação, esse "tudo estar na internet" implica nas vozes que anteriormente foram reprimidas pela edição da informação pelas mídias de massa.

Outro diretor menciona também como ponto que considera negativo o seguinte:

"Como algumas crianças têm uma defasagem de aprendizagem, os alunos não podem acessar com sucesso as máquinas, é a dificuldade que eles têm na própria leitura e escrita, pois como eles não identificam as letras, eles têm dificuldade em acessar seja o jogo pedagógico, até o manuseio" (D06).

Entretanto, acredita-se que a defasagem na aprendizagem não é decorrente da presença do laboratório de informática na escola, mas sim de falhas no próprio sistema de ensino, prejudicando, como aponta a professora, o sucesso com a informática. Cabe a necessidade de ajustar essas falhas, ou seja, encontrar alternativas de sanar essas defasagens que ainda permeiam o processo escolar.

Por fim, salienta-se a fala de um outro gestor, que afirma que

"Ponto negativo não tem, a não ser a preocupação com o roubo, mas do lado educacional não tem [...]” (D02).

Um discurso que demonstra outra necessidade social, a segurança nas escolas. Porém, essa questão não atinge necessariamente os processos de aprendizagem, pois suas implicações vão além da prática pedagógica.

\title{
3 Relação das TDR com os processos educativos
}

\begin{abstract}
"Porque no momento em que o professor sentar e ver que não é um bicho de sete cabeças, ele vai ver que dá pra trabalhar, é legal, é uma outra maneira, sai de um ambiente de sala de aula, fica mais interessante... Porque o aluno, na cabeça dele, é mais interessante até porque é mais interativo, então o professor vai ver que existe essa possibilidade de trabalhar. E tendo criatividade, pode trabalhar várias coisas..." (P02).
\end{abstract}

Para pensar sobre as relações, as contribuições e as associações das tecnologias nos processos educativos é preciso contar com vários tipos de apoio. Para esse tópico da pesquisa, 
foram usados os depoimentos de professores e monitores e também reflexões sobre as aulas observadas.

Muitas são as características reticulares (CASTELLS, 2005) das tecnologias que podem ser utilizadas em benefício dos processos de aprendizagem potencializando-os, pois, tendo criatividade, é possível "trabalhar várias coisas", citando a fala do professor acima. De acordo com Pozo (2002), as tecnologias multiplicam as possibilidades cognitivas do ser humano e permitem o acesso à nova cultura da aprendizagem, sendo, por isso, muito importante pensar na aproximação delas com os processos educativos formais.

Há que se refletir sobre as estratégias que estão sendo usadas na vinculação do laboratório com os ensinamentos objetivados. Nesse sentido, buscando identificar as relações entre as aulas do laboratório com os projetos da escola, foi questionado aos professores e laboratoristas se eles percebiam a existência de relações entre os projetos da escola e o uso do laboratório de informática.

Quando essa questão foi aplicada aos professores responsáveis pelo laboratório, dos sete entrevistados quatro mencionaram que não existiam relações entre os projetos da escola e as aulas no laboratório de informática e sim, apenas, entre as aulas do laboratório com as aulas de sala de aula, o que já é um grande passo:

\begin{abstract}
"O laboratório tá sendo usado para complementar as aulas dos professores. A cada 15 dias a escola tem reuniões pedagógicas, que eu sempre participo e dialogo com as outras professoras... aí eu sugiro atividades e sites para os professores acessarem em casa e descobrir algumas coisas que podem trabalhar com os alunos..." (P04).

"O ano passado nós trabalhamos em cima de projetos, agora esse ano nós ainda não estipulamos... Estipulamos e fizemos o tema 'o lixo', mas a coisa tá fluindo [...], porque a gente não força as professoras, as professoras que vêm... Esse ano estamos caminhando assim, de planejamentos mais curtinhos, mas o ano é longo, com certeza vamos ter que elaborar projetos sim, pra não ser só ir lá no laboratório..." (P06).

“Olha, até hoje eu não vi nenhuma. A informática trabalha diretamente com o professor em sala de aula, com o professor dentro do laboratório, mas com os projetos, no meu entender, não existe elo nenhum de ligação" (P07).

"Por enquanto vou dizer que não. Infelizmente a gente ainda não chegou a esse estágio, até porque começou a funcionar há três semanas atrás. E até as próprias professoras não tiveram oportunidade de conhecer o que tem pra elas aproveitarem, então é muito pouco tempo" (P01).
\end{abstract}

Já os outros três professores mencionam que existiam, sim, relações entre alguns projetos da escola com as aulas no laboratório de informática:

"O único projeto que nós temos aqui na escola que ta sendo relacionado com o laboratório é o projeto de filosofia. Então, o projeto de filosofia do professor [...] está sendo bem explorado, ele é um dos professores que mais utilizam o laboratório. [...] Além disso [de um software do Kelix que está sendo utilizado nesse projeto, que o professor não lembrava o nome], a gente trabalha também nesse projeto de filosofia o Tangran, mas vai ser mais adiante... o Gtans... Ah... e tem o Xadrez, que eu trabalho, é um projeto meio a parte, eu trabalho meia tarde com eles, duas horas" (P02). 


\begin{abstract}
"Agora nesses projetos últimos sim, inclusive a gente tem projeto de inclusão digital dos alunos e professores da escola. $\mathrm{O}$ ano passado quando a gente recebeu o laboratório, em 2007, nós montamos, dentro da nossa formação em serviço, um projeto de inclusão digital, e aí a gente fez cursos pros professores, pra esses professores trabalharem depois com os alunos" (P05).

"De acordo com o que os projetos estão acontecendo, os projetos da escola, eles buscam no laboratório mais um recurso, assim, para completar. Às vezes, o que tá acontecendo na sala de aula a gente vem aqui e sendo possível a gente contempla, e sempre é possível, é só achar o jeito né, o melhor caminho [...], é o complemento do que eles estão trabalhando em sala de aula" (P03).
\end{abstract}

De acordo com os relatos observados, percebe-se que existe pouca relação do laboratório com os projetos realizados pelo todo da escola. Mesmo no discurso dos professores que falaram que existem relações entre eles, percebe-se somente a menção de três projetos que utilizam a informática como elemento basilar. Acredita-se que isso acontece porque as escolas ainda estão passando por um processo de adaptação, de acordo com Lévy (1999), que ainda não lhes dá condições de integrarem o laboratório, a informática, com esses projetos de âmbito maior.

\title{
Algumas considerações
}

Na medida em que se reconhece a escola como um espaço legítimo de formação do cidadão e, também, de inclusão digital, torna-se fundamental analisar e refletir a forma como as tecnologias têm sido apropriadas pela dinâmica educacional, elementos que foram contemplados pela pesquisa de campo realizada.

Podemos concluir que a gestão reconhece a importância da inclusão digital de suas escolas, porém existe receio por parte dos professores em utilizar as tecnologias pelo fato de não dominarem a técnica ou de não reconhecerem o potencial dessas ferramentas na dinâmica escolar.

Esses pontos negativos e positivos apresentados pelos gestores serviram como elementos capazes de colaborar para uma percepção acerca das relações, contribuições e associações das TDR nos processos educativos nas escolas envolvidas. Procurou-se dar uma visão tanto dos pontos positivos quanto dos considerados negativos, com a intenção de que o panorama fosse mostrado tal como ele realmente é e com a finalidade também de que alguns elementos fossem explorados e clareados.

Enfim, consideramos que apesar do reconhecimento das dificuldades apresentadas pelos gestores das escolas, muitos são os benefícios impressos por essas tecnologias na dinâmica escolar. Cada vez mais surge a importância de cursos de formação docente na área de inclusão digital, buscando potencializar a utilização dessas tecnologias nessas escolas e aprimorar a concepção que os educadores e os gestores possuem sobre informática na educação. 


\section{Referências}

BONILLA, Maria Helena. Educação e Inclusão Digital. GEC: Grupo de Pesquisa em Educação, Comunicação e Tecnologias, 2004. Disponível em: <http://twiki.im.ufba.br/bin/view/GEC/MariaHelenaBonilla〉. Acesso em 10 Out. 2007.

CASTELLS, Manuel. A internet e Sociedade em Rede. In: MORAES, Dênis de (org). Por uma outra comunicação - Mídia, mundialização cultural e poder. 3 ed. Rio de Janeiro: Record, 2005, p.225-231.

FREIRE, Paulo. Educação como prática da liberdade. 6 ed. Rio de Janeiro: Paz e Terra, 1976.

LEMOS, André. Cibercultura. Alguns Pontos para compreender a nossa época. In: LEMOS, André; CUNHA, Paulo (orgs). Olhares sobre a Cibercultura. Sulina: Porto Alegre, 2003. Disponível em: <http://www.facom.ufba.br/ciberpesquisa/andrelemos/cibercultura.pdf>. Acesso em: 01 Mai. 2007.

LÉVY, Pierre. Cibercultura. São Paulo: Editora 34, 1999.

MEC, Ministério da Educação. ProInfo - Programa Nacional de Informática na Educação. Disponível em <http://www.ProInfo.mec.gov.br/>. Acesso em Julho de 2007.

POZO, Juan Ignacio. Aprendizes e Mestres: A nova cultura da aprendizagem. Porto Alegre: Artmed Editora, 2002.

PRETTO, Nelson de Luca. Políticas públicas educacionais no mundo contemporâneo. Liinc em revista. Março, 2005 Disponível em: <http://www.liinc.ufrj.br/revista/revista _tres/pretto.pdf>. Acesso em: 10 Jun. 2005

TEIXEIRA, Adriano Canabarro. Formação Docente e Inclusão Digital: a análise do processo de emersão tecnológica de professores. Tese (Doutorado em Informática na Educação) - Programa de Pós Graduação em Informática na Educação da Universidade de Federal do Rio Grande do Sul, Rio Grande do Sul, 2005.

TRENTIN, Marco; TEIXEIRA, Adriano Canabarro, DE MARCHI, Ana Bertoletti; ROSSETO, Maria Célia. Formação docente: um exercício de autonomia colaborativa. RENOTE - Revista Novas Tecnologias na Educação, Nov. 2007. 